\title{
Epidural abscess after epidural catheter for pain release during pancreatitis
}

\author{
A. R. Heller, M. RAgaller and T. KoCH \\ Department of Anaesthesiology and Intensive Care Medicine, University Hospital Carl Gustav Carus, Dresden, Germany
}

\begin{abstract}
Background: Despite knowledge about compromised host defence in the course of diabetes mellitus and pancreatitis, epidural analgesia (EA) is recommended for pain management during pancreatitis.

Case report: We present the case of a diabetic patient with pancreatitis who developed an epidural abscess after 3 days with an epidural catheter. Natural killer and T-helper cell counts were distinctively reduced in the absence of HIV serology. Furthermore, a synthesis failure of the liver was observed and evidenced by low cholinesterase, low whole protein fraction and low antithrombin III in the peripheral blood.
\end{abstract}

Conclusion: We suggest that the combination of pancreatitis, diabetes and compromised immunity might be a contraindication to epidural analgesia.

Key words: Epidural catheter; epidural abscess; epidural hematoma; pancreatitis; diabetes; immune deficiency; natural killer cells.
$\mathrm{D}^{\mathrm{s}}$ URING PANCREATITIS the cascade of inflammation is activated resulting in the release of cytokines, e.g. tumour necrosis factor (TNF) $)_{\alpha}$ interleukin (IL)-1 and IL-6 from macrophages and monocytes $(1,2)$. These early inflammatory cytokines act both locally and systemically causing the release of secondary wave cytokines, expression of adhesion molecules, chemotaxis of leukocytes and the synthesis of lipid mediators (3) and reactive oxygen species (4). The resulting increased capillary permeability is followed by haemodynamic deterioration, oedema formation and organ failure such as acute respiratory distress (5). Despite leukocytosis and upregulation of the inflammatory network during pancreatitis, several Tlymphocytic subsets (6) and HLA-DR expression on monocytes (CD14) have been observed to be downregulated in the peripheral blood, which correlated with mortality (7). Chronic pancreatitis can induce failure of the endocrine pancreas function by downregulation of digestive enzymes, resulting in secondary diabetes mellitus and compromised immunity $(8$, 9).

Despite the evidence of compromised immune function during acute pancreatitis, epidural analgesia (EA) is recommended for treatment of concomitant pain in the literature $(10,11)$ and in a consensus paper of the German society of digestive and endocrinological diseases (12). Since cases of epidural haema- toma and abscess have been reported in pancreatitis and diabetic patients (13-15), Malfertheiner and colleagues restrict the use of EA for pain relief during chronic pancreatitis only to selected cases (16).

We report the case of an epidural haematoma and abscess after lumbar EA in a patient suffering from acute pancreatitis and diabetes mellitus.

\section{Case report}

A 48-year-old man with a history of alcohol use and diabetes mellitus was brought to an outlying district hospital with clinical, biochemical and ultrasonographical signs of acute exacerbation of chronic pancreatitis. He received a central venous line (right internal jugular vein) for parenteral nutrition at day 1 . On the 3rd day in hospital an epidural catheter was inserted in the $\mathrm{L}_{1-2}$ interspace for pain management. The epidural catheter was accidentally dislocated and consequently removed on the 5th day without any signs of inflammation or swelling. At the same time the site of central venous puncture was inflamed and the central line was changed to the left internal jugular vein. The following day (6th) swelling and inflammation at the site of epidural puncture occurred. Since a pancreatic abscess was suspected, a conventional computer tomogram (CT) of the upper abdomen was performed on day 7 which did not reveal 
any cause for elevated temperatures, but surprisingly a right-sided pneumothorax was found which had no impact on blood gases in the spontaneously breathing patient. Staphylococcus aureus (STAU) was grown from the epidural puncture site, which was systemically treated with cefotiam.

Slight motor blockade of the left leg during day 9 was the cause to admit the patient to our ICU and to perform magnetic resonance imaging (MRI). Blood tests showed: Haemoglobin $6.6 \mathrm{mmol} / \mathrm{l}$, haematocrit 0.31, WBC $14.2 \mathrm{Gpt} / \mathrm{l}$, fibrinogen $6.3 \mathrm{~g} / 1$ and antithrombin III 56\%, glucose $17.8 \mathrm{mmol} / \mathrm{l}$. MRI (Figs. 1 and 2) showed a subacute haematoma stretching from the 12th thoracic to the 2nd lumbar vertebra with insignificant compression of the spinal cord. Since the motor blockade was only slight and sensory function was not affected, no neurosurgical intervention was performed. The patient was systemically treated with piperacilline plus sulbactam and symptoms of spinal cord compression were monitored care-

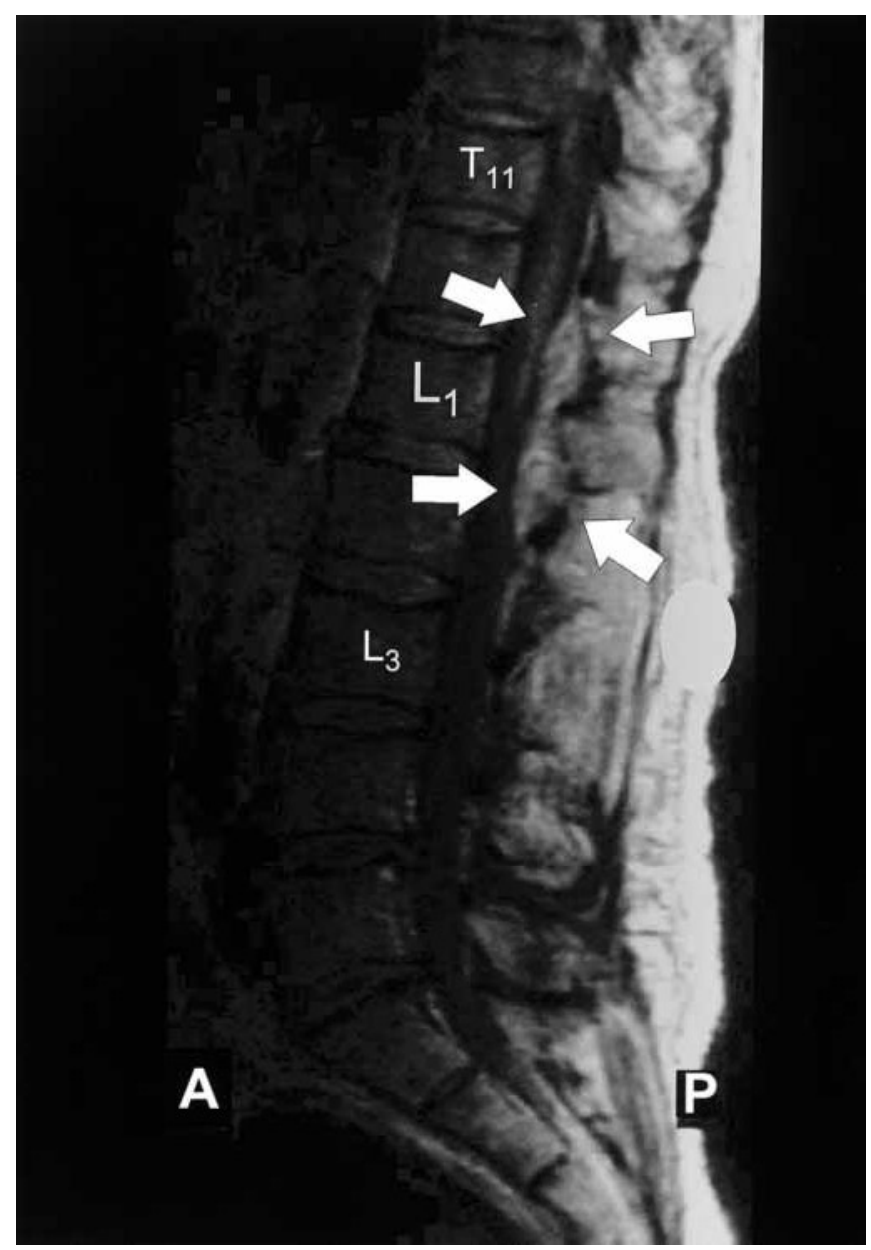

Fig. 1. Sagittal magnetic resonance image of the vertebral column. The epidural abscess stretches from the 12th thoracic to the 2nd lumbar vertebra (arrows).

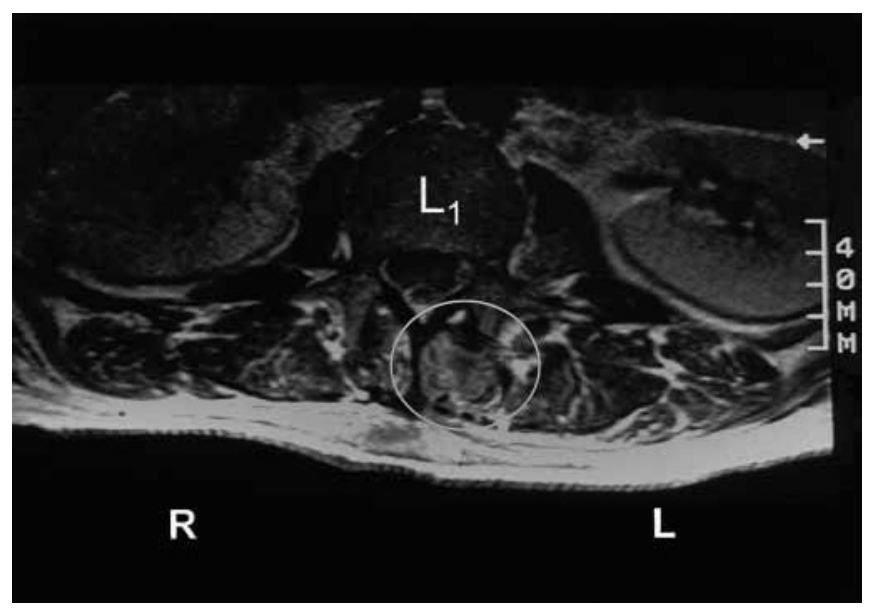

Fig. 2. Transversal magnetic resonance image of the vertebral column at level L1. The superinfected epidural haematoma includes all levels from the epidural space, including the subcutis (circle).

fully. Besides the inflammation at the site of the first central line and EA puncture, the right hand ankle in which an arterial line was previously placed was observed to be painfully swollen. At that time body temperatures was $39.1^{\circ} \mathrm{C}$, C-reactive protein $195 \mathrm{mg} /$ 1 and leukocytes $13.8 \mathrm{Gpt} / 1$.

A control chest $X$-ray on day 10 showed recovery from pneumothorax, blood cultures were sterile, whereas contamination of the EA-puncture site with STAU continued. Measurements of $35 \mu \mathrm{mol} / 1$ of cholinesterase, $57 \mathrm{~g} / 1$ of whole protein fraction and $57 \%$ of antithrombin III indicated liver synthesis insufficiency. Fever dropped the next day (day 11 after initial admission) and ultrasound of the pancreas and levels of amylase and lipase indicated a decrease of pancreatitis activity. Since motor blockade persisted, intralaminar fenestration with debridement and drainage of the abscess as well as local rinsing with gentamicin solution was performed. The systemic antibiotic therapy was continued. On the 1st postoperative day (day 13) the neurological deficit fully recovered. HIV serology was negative, but NK-cell and T-helper cell counts were reduced to $18 / \mu \mathrm{l}$ and to $441 / \mu l$ respectively. The patient's condition improved during the following postoperative days and he was discharged from the ICU on the 4 th postoperative day.

\section{Discussion}

In recent years alterations of the immunological acute phase reaction have been observed during pancreatitis. On the one hand, experimental studies provided evidence that pancreatitis induces pro-inflammatory cytokines which activate granulocytes, also in distant 
organ systems such as the lung, initiating pulmonary damage (17) by elastase and phospholipase $A_{2}$ release $(3,18)$; on the other hand, pancreatitis associated with downregulation of certain host defence systems was observed $(6,7)$. Moreover, diabetes mellitus may be accompanied with immunosuppression $(8,9)$. Keeping in mind the contraindication for EA in immune compromised septic patients $(19,20)$ and the fact that epidural abscesses spontaneously occur during immunodepression, even without epidural puncture (21) acute pancreatitis should perhaps be considered a contraindication for EA. Likewise, the association between certain coagulation parameters and diabetes mellitus (22) must carefully be taken into account, if EA is performed in diabetic patients.

In the current case, EA was performed during acute pancreatitis in a diabetic patient with history of alcohol use and with signs of impaired liver synthesis function. Since early diagnosis of epidural abscess is essential for favourable outcome $(23,24)$ symptoms of spinal cord compression were monitored carefully after EA-catheter removal. Growth of STAU from epidural abscesses, as observed in the current case, is common in EA (25). After MRI and admittance to our ICU the patient was at first conservatively treated. On the 4th day in our ICU intralaminar fenestration with debridement and drainage of the epidural abscess was performed and the patient fully recovered within 4 days.

Pancreatitis induces systemic inflammation (2) and is associated with the modulation of the acute phase reaction. The latter is characterised by an expression of protective organ-preserving proteins $(26,27)$ which, however, are not capable of completely counteracting the pro-inflammatory stimulation. Particularly reduced T-cell subpopulations, as observed in the current case, and which have also been reported by Pezzilli et al. in acute pancreatitis (6) such as total and $\mathrm{CD} 4+, \mathrm{CD} 8+, \mathrm{CD} 3+\mathrm{DR}-$, and CD3- DR + lymphocytes, increase the susceptibility to additional infections and may explain the impaired host defence resulting in the observed infectious complications with Gram-positive bacteria in the described case of pancreatitis.

\section{Conclusion}

We present a diabetic patient with pancreatitis who developed an epidural abscess after 3 days with an epidural catheter. Patients with diabetes, alcohol abuse and pancreatitis may be severely immunocompromised. We suggest that pancreatitis may be a contraindication to epidural analgesia.

\section{References}

1. Norman J. The role of cytokines in the pathogenesis of acute pancreatitis. Am J Surg 1998: 175: 76-83.

2. Denham W, Yang J, Norman J. Evidence for an unknown component of pancreatic ascites that induces adult respiratory distress syndrome through an interleukin-1 and tumor necrosis factor-dependent mechanism. Surgery 1997: 122: 295-301.

3. Heller A, Koch T, Schmeck J, van Ackern K. Lipid mediators in inflammatory disorders. Drugs 1998: 55: 487-496.

4. Murakami H, Nakao A, Kishimoto W, Nakano M, Takagi H. Detection of $\mathrm{O}_{2}$-generation and neutrophil accumulation in rat lungs after acute necrotizing pancreatitis. Surgery 1995: 118: 547-554.

5. Temmesfeld-Wollbruck B, Walmrath D, Grimminger F, Seeger W. Prevention and therapy of the adult respiratory distress syndrome. Lung 1995: 173: 139-164.

6. Pezzilli R, Billi P, Beltrandi E, Maldini M, Mancini R, Morselli Labate AM et al. Circulating lymphocyte subsets in human acute pancreatitis. Pancreas 1995: 11: 95-100.

7. Richter A, Nebe T, Wendl K, Schuster K, Klaebisch G, Quintel $\mathrm{M}$ et al. HLA-DR expression in acute pancreatitis. Eur J Surg 1999: 165: 947-951.

8. Litherland SA, Xie XT, Hutson AD, Wasserfall C, Whittaker DS, She JX et al. Aberrant prostaglandin synthase 2 expression defines an antigen-presenting cell defect for insulin-dependent diabetes mellitus. J Clin Invest 1999: 104: 515-523.

9. Tsujino M, Kinpara I, Nakamura T, Suda T, Saitou Y, Kudou $\mathrm{H}$ et al. Peripheral lymphocyte subset of patients with pancreatic diabetes mellitus - about a decreased ratio of T-LGL and ability of host defense. Kansenshogaku Zasshi 1996: 70: 325-330.

10. Senninger N, Busse G, van Aken $H$. The patient with respiratory problems. Chirurg 1997: 68: 662-669.

11. Niesel HC, Klimpel L, Kaiser H, Bernhardt A, al-Rafai S, Lang U. Epidural blockade for analgesia and treatment of acute pancreatitis. Reg Anesth 1991: 14: 97-100.

12. Mössner J, Keim V, Niederau C, Büchler M, Singer M, Lankisch PG et al. Leitlinien zur Therapie der chronischen Pankreatitis. Konsensuskonferenz der Deutschen Gesellschaft für Verdauungs- und Stoffwechselkrankheiten. Z Gastroenterol 1998: 36: 359-367.

13. Gustafsson H, Rutberg H, Bengtsson M. Spinal haematoma following epidural analgesia. Report of a patient with ankylosing spondylitis and a bleeding diathesis. Anaesthesia 1988: 43: 220-222.

14. Mahendru V, Bacon DR, Lema MJ. Multiple epidural abscesses and spinal anesthesia in a diabetic patient. Reg Anesth 1994: 19: 66-68.

15. Yamaguchi M, Kawakubo A, Ide R, Hara K, Sumikawa K. Epidural abscess associated with epidural block in a patient with immunosuppressive disease. Masui 1999: 48: 506-508.

16. Malfertheiner P, Dominguez-Munoz JE, Buchler MW. Chronic pancreatitis: management of pain. Digestion 1994: 55 (Suppl 1): 29-34.

17. O'Donovan DA, Kelly CJ, Bouchier-Hayes DM, Grace P, Redmond HP, Burke PE et al. Alpha-1-antichymotrypsin is an effective inhibitor of pancreatitis-induced lung injury. Eur J Gastroenterol Hepatol 1995: 7: 847-852.

18. Hirano T, Manabe T. A new synthetic elastase inhibitor, EI546 , protects lungs but not pancreas in caerulein-induced pancreatitis in the rat. Med Sci Res 1992: 20: 473-474.

19. Gaiser RR. Contraindications for epidural blockade. In: Longnecker DE, Tinker G, Morgan E jr., eds. Principles and practice of anesthesiology. 2nd edn. St. Louis: Mosby, 1998: 1402-1405. 
20. Breivik H. Neurological complications in association with spinal and epidural analgesia - again. Acta Anaesthesiol Scand 1998: 42: 609-613.

21. Kovalik EC, Raymond JR, Albers FJ, Berkoben M, Butterly DW, Montella B et al. A clustering of epidural abscesses in chronic hemodialysis patients: Risks of salvaging access catheters in case of infection. J Am Soc Nephrol 1996: 7: 22642267.

22. Duncan BB, Schmidt MI, Offenbacher S, Wu KK, Savage PJ, Heiss G. Factor VIII and other hemostasis variables are related to incident diabetes in adults. The atherosclerosis risk in communities (ARIC) study. Diabetes Care 1999: 22: 767772.

23. Lindner A, Warmuth-Metz M, Becker G, Troyka VV. Iatrogenic spinal epidural abscesses: Early diagnosis essential for good outcome. Eur J Med Res 1997: 28: 201-205.

24. Kvalsvik O, Borchgrevink PC, Gisvold E. Epidural abscess following continuous epidural analgesia in two traumatized patients. Acta Anaesthesiol Scand 1998: 42: 732-735.

25. Kindler $\mathrm{CH}$, Seeberger MD, Staender SE. Epidural abscess complicating epidural anesthesia and analgesia. An analysis of the literature. Acta Anaesthesiol Scand 1998: 42: 614-620.

26. Fiedler F, Croissant N, Rehbein C, Iovanna JL, Dagorn JC, van Ackern $\mathrm{K}$ et al. Acute-phase response of the rat pancreas protects against further aggression with severe necrotizing pancreatitis. Crit Care Med 1998: 26: 887-894.

27. Heller A, Fiedler F, Schmeck J, Lück V, Iovanna JL, Koch T. Pancreatitis associated protein develops protective properties on leukocyte induced vascular damage in the lung. Anesthesiology 1999: 91: 1408-1414.

Address:

Axel R. Heller M.D.

Department of Anaesthesiology and Intensive Care Medicine University Hospital Carl Gustav Carus

Fetscherstrasse 74

D-01307 Dresden

Germany

e-mail: heller-a@rcs.urz.tu-dresden.de 